\title{
Immune function in female elite rowers and non-athletes
}

David C Nieman, Sandra L Nehlsen-Cannarella, Omar R Fagoaga, Dru A Henson, Michael Shannon, Jannica M E Hjertman, Robert L Schmitt, Marc R Bolton, Melanie D Austin, Brian K Schilling, Richard Thorpe

\begin{abstract}
Objective-To compare immune function in female rowers and controls in the resting state, and then correlate the results with a two month history of upper respiratory tract infection (URTI).

Methods-Subjects included 20 elite female rowers located at the ARCO Olympic Training Centre in Chula Vista, California, and 19 non-athletic female controls. These two groups were compared cross sectionally for immune function and infection rates.

Results-Granulocyte/monocyte phagocytosis, oxidative burst activity, and plasma cytokine concentrations (interleukin-6, tumour necrosis factor- $\alpha$, and interleukin-1 receptor antagonist) did not differ significantly between groups. Phytohaemagglutinin induced lymphocyte proliferative response (adjusted whole blood method) was significantly higher $(31 \%$ and $36 \%$ for optimal and suboptimal concentrations respectively) in rowers than in controls. Natural killer cell activity was substantially higher (1.6-fold for total lytic units) in the female rowers than in controls. Two month health logs disclosed $5.2(1.2)$ and 3.3 (1.1) days with URTI symptoms for the rowers and controls respectively $(p=0.268)$. For all 39 subjects combined, and for the 20 rowers separately, none of the immune parameters correlated significantly with number of days with URTI symptoms.

Conclusions-In this cross sectional comparison of elite female rowers and nonathletes, a group difference was found for natural killer cell activity and phytohaemagglutinin induced proliferative response (whole blood technique), but not other measures of immune function. The number of days with URTI symptoms during the spring season did not differ between groups, and variations in blood measures of immunity were unrelated to URTI.
\end{abstract}

(Br F Sports Med 2000;34:181-187)

Keywords: rowing; immune system; neutrophil; lymphocyte; phagocytosis; natural killer cell

Athletes, according to some investigators, are at increased risk of upper respiratory tract infection (URTI) during periods of increased training or after competitive events. ${ }^{1-6}$ On the other hand, athletes often report in surveys that they experience decreased rates of infection compared with non-athletes during periods of normal training. ${ }^{37}$ Attempts so far to compare resting immune function in athletes and non-athletes have failed to provide compelling evidence that athletic endeavour is linked to clinically important changes in immunity. ${ }^{38}$ The adaptive immune system (in particular, measures of $\mathrm{T}$ and $\mathrm{B}$ cell function) does not appear to be affected by intensive and prolonged exercise training in young to middle aged adults, although data do not present a clear picture at present. ${ }^{9-12}$ The innate immune system responds differentially to the chronic stress of intensive exercise, with enhancement of natural killer cell activity (NKCA) and suppression of neutrophil function, but this may depend on the intensity of training. ${ }^{9-17}$

Even when significant changes in the functional activity of blood immune cells have been observed in athletes, investigators have had little success in linking these to a higher incidence of infection and illness. ${ }^{15}{ }^{18-21}$ Pyne et $a l^{15}$, for example, reported that elite swimmers undertaking intensive training had a significantly lower neutrophil oxidative activity - that is, bacterial killing capacity — at rest than age and sex matched sedentary controls, and that function was further suppressed during the period of strenuous training before national level competition. Nonetheless, URTI rates did not differ between the swimmers and sedentary controls.

Elite rowers are capable of extremely high oxygen consumption and ventilation rates. ${ }^{22-26}$ During race events, about $70 \%$ of the body's muscle mass is involved for 5.5-8 minutes at an average power of $450-550 \mathrm{~W}^{25}$ In high load training phases before World Championships, training volume reaches 190 minutes a day, of which between 55 and $65 \%$ is rowing and the rest weight lifting, stretching, and calisthenics. Rowing training is primarily performed at moderate intensities, with $4-10 \%$ of total row time spent at high intensities. ${ }^{25}$ Because of the large amount of muscle mass used in rowing, stress hormones have been reported to reach extreme values. ${ }^{24}{ }^{26}$ Thus the immune systems of elite rowers may experience stressful changes on a regular basis that may be greater than those measured in other athletic groups. A report from the United Kingdom suggested that elite rowers have a high incidence of sickness after intensive training and competition, similar to that of marathon and
Accepted for publication 11 November 1999 
ultramarathon runners. ${ }^{27}$ In a one year retrospective study of 69 British rowers competing for the national team, the average days lost per athlete through illness was 6.5 , and through injury $12.8 .^{28}$

The immune function of elite rowers and non-athletic controls has not yet been measured, and no cross sectional comparison has focused on young female adults. In this investigation, the immune function of 20 female elite rowers and 19 non-athletic controls was compared in the resting state, and then related to a two month history of URTI in an attempt to identify an immune marker that could identify those at high URTI risk.

\section{Methods}

SUBJECTS

The subjects were 20 elite female rowers located at the Olympic Training Centre in Chula Vista, California, and 19 non-athletic female controls (of similar age and body mass index, and selected from the surrounding community). To be included in the study, athletes and controls had to meet these selection criteria: (a) in good health, with no known diseases including diabetes, cancer, or heart disease; (b) not currently on a reducing diet, and for controls, not exercising vigorously (less than three moderate to vigorous aerobic sessions longer than 30 minutes a week); (c) not using medications known to affect immune function and inflammation; (d) not using vitamin/mineral supplements in excess of $100 \%$ of recommended dietary allowances on a regular basis within two weeks of testing; (e) not using cigarettes or imbibing excessive amounts of alcohol. Written informed consent was obtained from each subject, and the experimental procedures were in accordance with the policy statements of the American College of Sports Medicine and the institutional review board of Appalachian State University.

RESEARCH DESIGN

In this cross sectional comparison, immune function and two month URTI rates (mid-March to mid-May) were contrasted between female rowers and controls. Blood samples were collected from all subjects during one morning in late May, about three months before the 1998 World Championships. At this time, the female rowers were averaging 12 to 13 training sessions a week of 90-120 minutes duration, and were estimated by the coach to be about $5 \%$ above projected race times.

CARDIORESPIRATORY FITNESS ASSESSMENT Maximal oxygen consumption, ventilation, and respiratory rate were measured in the rowers using a SensorMedics VMax29 metabolic cart (Yorba Linda, California, USA) during a $1500 \mathrm{~m}$ standard time trial row on the Concept II-B ergometer (Norrisville, Vermont, USA). ${ }^{30}$ Maximal heart rate was measured during this test using Polar Vantage X1 chest strap transmitters (Polar
Electro Inc, Woodbury, New York, USA). The same parameters were measured in the controls during a maximal graded cycle ergometer test according to protocols outlined previously. ${ }^{31}$ All cardiorespiratory measurements were made within one month of blood sampling.

\section{BLOOD SAMPLES}

Blood samples were withdrawn at 0600-0800 from an antecubital vein with subjects in the seated position (after 10-15 minutes of rest). All samples were processed immediately for same day analysis, except for those for plasma cytokine analysis, which were frozen at $-80^{\circ} \mathrm{C}$ for later analysis. Routine complete blood counts were performed by a clinical haematology laboratory (Lab Corp, Burlington, North Carolina, USA), and provided leucocyte subset counts, haemoglobin, and packed cell volume.

\section{PHYTOHAEMAGGLUTININ (PHA) INDUCED}

LYMPHOCYTE PROLIFERATION

The mitogenic response of lymphocytes was determined in whole blood culture using PHA at optimal and suboptimal doses previously determined by titration experiments. ${ }^{112932}$ Heparinised venous blood was diluted 1:10 with complete medium (RPMI 1640 supplemented with $10 \%$ heat inactivated fetal calf serum, penicillin, streptomycin, L-glutamine, and 2-mercaptoethanol; Sigma Chemical Company, St Louis, Missouri, USA). PHA was prepared in RPMI 1640 medium, at a concentration of $1 \mathrm{mg} / \mathrm{ml}$, and then further diluted with complete medium to the optimal and suboptimal working concentrations (25 and $6.25 \mu \mathrm{g} / \mathrm{ml}$ respectively). A $100 \mu \mathrm{l}$ aliquot of diluted blood was dispensed into each of triplicate wells of a 96 well, round bottomed microtitre plate. To each of these was added $100 \mu$ of the mitogen at the appropriate dose. Control wells received complete medium instead of mitogen. After 72 hours of incubation at $37^{\circ} \mathrm{C}$, the cells were pulsed with $1 \mu \mathrm{Ci}$ [methyl $-{ }^{3} \mathrm{H}$ ] thymidine (New England Nuclear, Boston, Massachusetts, USA) prepared with RPMI 1640. After pulsing, cells were incubated for an additional four hours before harvesting. Radionucleotide incorporation was assessed by liquid scintillation counting (Tri-Carb liquid scintillation analyzer, model 2500 TR Series; Packard Instruments Company, Meriden, Connecticut, USA) using Scinti Verse (Fisher Scientific, Pittsburgh, Pennsylvania, USA) as the scintillation cocktail. Background counts from control wells were subtracted from the mitogen induced counts. Whole blood data were adjusted for $\mathrm{T}$ cell concentration by dividing the total cpm by the number of $T$ cells in the assay well (based on the lymphocyte count and $\mathrm{T}$ cell percentage from the whole blood flow cytometry).

LYMPHOCYTE SUBSETS

The proportions of $\mathrm{T}$ cells $\left(\mathrm{CD}^{+}\right)$, $\mathrm{T}$ helper/ inducer $\left(\mathrm{CD}^{+} \mathrm{CD}^{+}\right)$, $\mathrm{T}$ helper/suppressor $\left(\mathrm{CD}^{+} \mathrm{CD}^{+}\right), \mathrm{B}$ cells $\left(\mathrm{CD} 19^{+}\right)$, and NK cells 
$\left(\mathrm{CD}^{-} \mathrm{CD} 16^{+} \mathrm{CD} 56^{+}\right)$were determined in whole blood preparations, and absolute numbers calculated using complete blood count data to allow group comparisons on blood concentrations of cells. Lymphocyte phenotyping was accomplished by four-colour fluorescent labelling of cell surface antigens with mouse anti-human monoclonal antibodies conjugated to fluorescein isothiocyanate (FITC), phycoerythrin (PE), peridinin chlorophyll protein (PerCP), and allophycocyanin (APC) using the MultiTest IMK kit monoclonal antibody reagents from Becton Dickinson (San Jose, California, USA). For immunophenotyping, $50 \mu 1$ heparinised whole blood was added to TRUECOUNT absolute count tubes (Becton Dickinson) and incubated with $20 \mu \mathrm{l}$ MultiTest reagent for 15 minutes at room temperature in the dark. After incubation, the cell suspension was lysed with $450 \mu \mathrm{l}$ lysing reagent (diethylene glycol and formaldehyde lysing reagent, MultiTest IMK kit) in a lyse-no-wash method for 15 minutes at room temperature in the dark. After incubation, the cells were analysed on a Becton Dickinson FACSCalibur flow cytometer. After acquisition, the cells were analysed using MultiSet software (Becton Dickinson).

LEUCOCYTE PHAGOCYTOSIS/OXIDATIVE BURST ASSAYS

The phagocytosis assay used FITC labelled bacteria (Staphylococcus aureus; Molecular Probes, Eugene, Oregon, USA) to quantify the degree of phagocytosis by granulocytes and monocytes. ${ }^{29}$ Monocyte and granulocyte percentages were determined using four-colour flow cytometric phenotyping (CD3-FITC, CD8-PE, CD45-PerCP, and CD4-APC). To determine the extent of oxidative burst exhibited by granulocytes and monocytes, we used 2',7'-dichlorodihydrofluorescein diacetate (DCF-DA; Molecular Probes), a nonfluorescent molecule that is oxidised to green fluorescent dichlorofluorescein (DCF) as oxygen radicals are generated in the oxidative burst in response to a challenge with $S$ aureus. Bioparticle reagents of unlabelled and labelled $S$ aureus were suspended in phosphate buffered saline at a working concentration of $1.6 \times 10^{6}$ bioparticles/ $\mu$ l. After the determination of the number of phagocytic cells in $100 \mu \mathrm{l}$ whole blood and the addition of 117 FITC-labelled bacteria per cell, the mean channel fluorescence (FITC) was analysed to determine the degree of engulfed bacteria. To determine the oxidative burst activities, either DCF-DA (final concentration, $100 \mu \mathrm{M}$; basal activity level) or DCF-DA and 117 unlabelled bioparticles per cell (stimulated activity level) were added to $100 \mu \mathrm{l}$ whole blood. After incubation of the samples for 60 minutes $\left(37^{\circ} \mathrm{C}\right)$ in the dark, lysing of the red blood cells, centrifugation, and resuspension of the pellets, the samples were acquired on the flow cytometer. For each sample, 10000 phagocytes (monocytes and granulocytes) were acquired. Oxidative burst activity was determined by subtracting basal levels from the stimulated levels.
NATURAL KILLER CELL CYTOTOXIC ACTIVITY (NKCA)

NKCA was assessed using the chromium release assay. ${ }^{33}$ Peripheral blood mononuclear cells were isolated from heparinised blood by density gradient centrifugation with Ficoll and sodium diatrivoate (American Red Cross, Washington DC, USA). ${ }^{51} \mathrm{Cr}$ labelled K562 target cells were then added $\left(1 \times 10^{4}\right)$ to each of the wells containing effector cells to yield $20: 1$, $10: 1$, and 5:1 effector to target (E:T) ratios. The assay was performed in triplicate in "V" bottomed microtitre plates (Costar, Cambridge, Massachusetts, USA). The microtitre plates were then incubated for four hours at $37^{\circ} \mathrm{C}$ in a $5 \% \mathrm{CO}_{2}$ incubator. At the end of the incubation, the plates were centrifuged for five minutes at $1500 \mathrm{rpm}$, the supernatants harvested on to Skatron harvesting frames (Skatron, Sterling, Virginia, USA), and the level of radioactivity measured in a Packard TriCarb liquid scintillation analyser model 2500 TR series. Total release of ${ }^{51} \mathrm{Cr}$ was determined by counting an aliquot of resuspended cells in 100 ul 1\% Triton-X100 (Sigma). Spontaneous release was determined by counting the radioactivity in the supernatant of labelled target cells cultured in medium alone. Percentage lysis was calculated using the mean cpm of triplicate values for each E:T ratio and the following formula:

$$
\% \text { lysis }=\frac{\mathrm{cpm}(\text { test })-\mathrm{cpm}(\text { spontaneous })}{\mathrm{cpm}(\text { total })-(\text { spontaneous })} \times 100
$$

Results were then normalised by conversion to lytic units, calculated as the number of effector cells required to lyse $20 \%$ of 5000 target cells, and reported as the number of lytic units contained in $10^{7}$ cells. $^{33}$

CYTOKINE MEASUREMENTS

Plasma interleukin-6 (IL-6) and tumour necrosis factor alpha (TNF- $\alpha$ ) were measured with enzyme immunoassay kits (Immunotech, Westbrook, Maine, USA). A standard curve was constructed for each run for each cytokine using standards provided in the kits. Concentrations for both controls and plasma samples were generated from standard curves using linear regression analysis. Assays were conducted in a two step "sandwich" enzyme immunoassay in which samples and standards were incubated in a 96 well microtitre plate coated with a cytokine capturing antibody. After appropriate incubation times, the wells were washed and a second detection antibody conjugated to acetylcholinesterase (IL-6) or alkaline phosphatase (TNF- $\alpha$ ) was added. The plates were incubated and then washed, and the amount of bound enzyme labelled detection antibody was measured by adding a chromogenic substrate. The plates were then read at the appropriate wavelength $(405 \mathrm{~nm})$. Total plasma interleukin-1 receptor antagonist (IL-1 ra) was measured with a quantitative sandwich enzyme linked immunosorbent assay (ELISA) technique, using monoclonal antibodies specific for IL-1ra as capture antibodies (R\&D Systems, Inc, Minneapolis, 
Minnesota, USA). A standard curve was constructed from standards run with the samples.

\section{HEALTH LOGS}

Log books for daily recording of health problems were given to each subject two months before blood sampling (mid-March to mid-May). Subjects recorded health problems each day of the two month period with codes used in a previous study. ${ }^{29}$ The coded health problems included: (1) no health problems today; (2) cold symptoms (runny stuffy nose, sore throat, coughing, sneezing, coloured discharge; (3) flu symptoms (fever, headache, general aches and pains, fatigue and weakness, chest discomfort, cough); (4) nausea, vomiting, and/or diarrhoea; (5) muscle, joint, or bone problems/injury; (6) other health problems (describe). The severity of symptoms was rated by subjects as mild, moderate, or severe. The number of days with URTI symptoms was calculated for each subject, with days counted only if two or more consecutive days of cold or flu symptoms were reported.

Table 1 Subject characteristics

\begin{tabular}{|c|c|c|c|}
\hline & Rowers $(n=20)$ & Non-athletes $(n=19)$ & $p$ Value \\
\hline Age (years) & $22.6(0.5)$ & $24.6(0.8)$ & 0.040 \\
\hline Height $(\mathrm{cm})$ & $181 \quad(1)$ & 163 (2) & $<0.001$ \\
\hline Body mass (kg) & $75.5(1.5)$ & $58.9(2.4)$ & $<0.001$ \\
\hline Body mass index $\left(\mathrm{kg} / \mathrm{m}^{2}\right)$ & $23.1(0.4)$ & $22.0(0.5)$ & 0.086 \\
\hline Body fat (\%) & $17.7(0.6)$ & $22.9(1.1)$ & 0.001 \\
\hline $\mathrm{VO}_{2} \mathrm{MAX}(\mathrm{ml} / \mathrm{min})$ & 3995 (93) & $2166 \quad(135)$ & $<0.001$ \\
\hline Haemoglobin $(\mathrm{g} / \mathrm{l})$ & $13.4(0.2)$ & $12.9(0.2)$ & 0.116 \\
\hline Packed cell volume (litres) & $39.1(0.6)$ & $38.0(0.6)$ & 0.248 \\
\hline VEMAX (litres/min) & $146 \quad(4)$ & $85.3(4.5)$ & $<0.001$ \\
\hline $\mathrm{HR}_{\mathrm{max}}$ (beats/min) & 189 (3) & 188 (2) & 0.743 \\
\hline $\mathrm{RR}_{\max }$ (breaths/min) & $60.8(1.2)$ & $47.5(1.9)$ & $<0.001$ \\
\hline General wellbeing (total points) & $68.9(3.1)$ & $80.7(3.5)$ & 0.016 \\
\hline
\end{tabular}

Values are mean (SE).

Table 2 Comparison of blood leucocyte and lymphocyte subset counts in female rowers and non-athletes

\begin{tabular}{llll}
\hline & Rowers $(n=20)$ & Non-athletes $(n=19)$ & $p$ Value \\
\hline Cell counts $\left(10^{9} / 1\right)$ & & & \\
Total leucocytes & $5.62(0.23)$ & $6.23(0.36)$ & 0.149 \\
Neutrophils & $2.93(0.19)$ & $3.39(0.30)$ & 0.197 \\
Monocytes & $0.43(0.03)$ & $0.47(0.03)$ & 0.328 \\
Total lymphocytes & $2.02(0.07)$ & $2.14(0.14)$ & 0.440 \\
$\quad$ T cells & $1.43(0.06)$ & $1.55(0.11)$ & 0.361 \\
T helper cells & $0.88(0.04)$ & $0.92(0.08)$ & 0.679 \\
T suppressor cells & $0.47(0.03)$ & $0.51(0.04)$ & 0.391 \\
NK cells & $0.30(0.03)$ & $0.24(0.03)$ & 0.128 \\
B cells & $0.24(0.02)$ & $0.31(0.04)$ & 0.154 \\
\hline
\end{tabular}

Values are mean (SE).

Table 3 Comparison of immune function in female rowers and non-athletes

\begin{tabular}{|c|c|c|c|}
\hline & Rowers $(n=20)$ & Non-athletes $(n=19)$ & $p$ Value \\
\hline \multicolumn{4}{|l|}{ Natural killer cell activity (\% lysis) } \\
\hline E:T $20: 1$ & $52.6(3.9)$ & $(4.0)$ & $<0.001$ \\
\hline $\mathrm{E}: \mathrm{T} 10: 1$ & $39.8 \quad(3.9)$ & $19.6(3.3)$ & $<0.001$ \\
\hline E:T 5:1 & $26.4 \quad(3.0)$ & $11.5(2.4)$ & $<0.001$ \\
\hline \multicolumn{4}{|l|}{ Phagocytosis, FITC (mean } \\
\hline Oxidative burst, DCF (mean & & & \\
\hline fluorescence channel) & 80.9 (6.1) & $88.3(4.9)$ & 0.354 \\
\hline $\mathrm{IL}-6(\mathrm{pg} / \mathrm{ml})$ & $1.45(0.55)$ & $3.16(1.12)$ & 0.183 \\
\hline Tumour necrosis factor $-\alpha(\mathrm{pg} / \mathrm{ml})$ & 21.4 & $28.6(8.8)$ & 0.455 \\
\hline IL-1 receptor antagonist $(\mathrm{pg} / \mathrm{ml})$ & $357 \quad(37)$ & 402 & 0.396 \\
\hline
\end{tabular}

Values are mean (SE). E:T, effector to target ratio; FITC, fluorescein isothiocyanate; DCF, dichlorofluorescein; IL, interleukin.

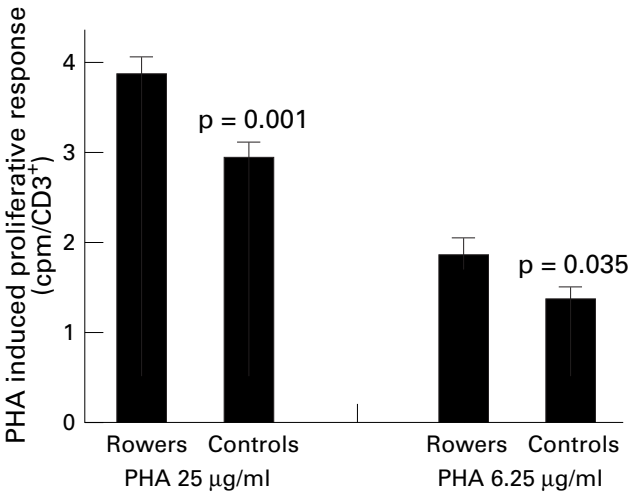

Figure 1 Phytohaemagglutinin (PHA) induced proliferative response (whole blood data adjusted as cpm for each $\mathrm{CD}^{+}$or $\mathrm{T}$ cell) was significantly greater in the elite female rowers than non-athletic controls at both optimal $(25$ $\mu \mathrm{g} / \mathrm{ml})$ and suboptimal $(6.25 \mu \mathrm{g} / \mathrm{ml})$ concentrations of PHA.

PSYCHOLOGICAL GENERAL WELLBEING

The general wellbeing schedule (GWBS) consists of 18 items which generate a total GWBS score and six subscale scores which indicate freedom from health concern, energy level, satisfying life, cheerful-depression, tensionrelaxation, and emotional stability. ${ }^{35}$ High test-retest reliability coefficients and correlational validity have been reported for the GWBS. ${ }^{36}$ Subjects answered each question on the basis of how they generally felt during the past three to four weeks (before blood withdrawal). A high score on the GWBS represents an expression of positive wellbeing and the absence of negative feelings.

\section{STATISTICAL ANALYSIS}

Statistical significance was set at the $p<0.05$ level, and values are expressed as mean (SE). Independent $t$ tests were calculated, comparing all measured variables for 20 rowers and 19 non-athletes. Pearson product-moment correlations were used to test the relation between the number of reported sick days, immune function, and psychological general wellbeing.

\section{Results}

Table 1 summarises subject characteristics for the 20 elite female rowers and 19 non-athletic controls. The rowers and non-athletes were of similar age (range 19-28 years and 18-32 years respectively) and body mass index (range 19.5-25.8 and 18.6-25.9 respectively). The rowers compared with non-athletes, however, were taller, heavier, and leaner. $\mathrm{Vo}_{2} \mathrm{MAX}(\mathrm{ml} /$ min) and maximal ventilation were $84 \%$ and $71 \%$ higher in the rowers than non-athletes. Haemoglobin concentration and packed cell volume did not differ significantly between groups. Psychological general wellbeing was significantly lower in the rowers than in the non-athletes, placing them in the "indicates stress problem" category. ${ }^{35} 36$

Blood leucocyte and lymphocyte subset counts were not significantly different between groups (table 2). Granulocyte/monocyte phagocytosis, oxidative burst activity, and plasma cytokine concentrations (IL-6, TNF, and IL-1 ra) did not differ significantly between groups (table 3). PHA induced lymphocyte 


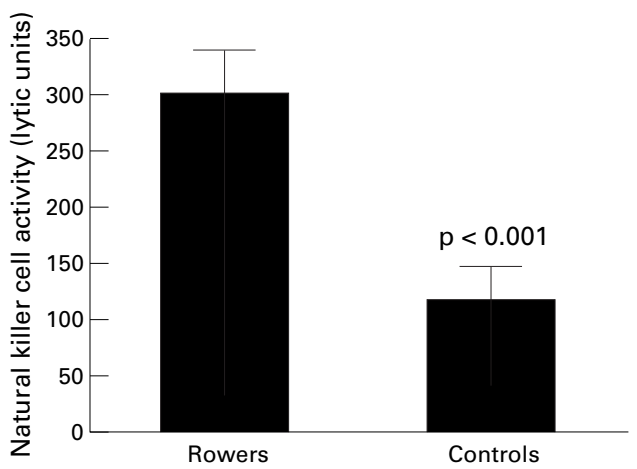

Figure 2 Natural killer cell activity (total lytic units per $10^{7}$ mononuclear cells) was significantly greater in the elite female rowers than non-athletic controls.

proliferation tended to differ between groups (55.4 (3.6) and 45.0 (3.8) cpm, optimal PHA concentration of $25 \mu \mathrm{g} / \mathrm{ml}$, for rowers and controls respectively; $\mathrm{p}=0.052 ; 26.7$ (2.7) and 20.2 (2.0) cpm, suboptimal PHA concentration of $6.25 \mu \mathrm{g} / \mathrm{ml}$, for rowers and controls respectively; $\mathrm{p}=0.066)$. When these data were adjusted for the number of $\mathrm{T}$ cells in the assay wells, proliferative responses at both the optimal and suboptimal concentrations were significantly higher $(31 \%$ and $36 \%$ respectively) in rowers than controls (fig 1). NKCA (fig 2) was substantially higher (1.6-fold for total lytic units) in the female rowers than the controls, and this was especially apparent at the lower E: $\mathrm{T}$ ratios (table 3).

The two month health logs showed 5.2 (1.2) and 3.3 (1.1) days with URTI symptoms for the rowers and controls respectively $(\mathrm{p}=$ 0.268). For all 39 subjects combined, and for the 20 rowers separately, none of the immune parameters listed in tables 2 and 3 or psychological general wellbeing correlated significantly with number of days with URTI symptoms.

\section{Discussion}

In this cross sectional comparison of 20 elite female rowers training at the Olympic Training Centre and 19 female non-athletes, a group difference was found for NKCA and PHA induced proliferative response (whole blood technique), but not other measures of immune function.

NATURAL KILLER CELL ACTIVITY

NKCA was significantly elevated in the rowers compared with non-athletes, which is similar to findings previously reported for male marathon runners ${ }^{11}$ male cyclists, ${ }^{12}{ }^{13}$ and elderly female endurance athletes. ${ }^{37}$ The data of Tvede $e t$ al ${ }^{12}$ support a higher NKCA in elite cyclists during the summer (intensive training period) than during the winter (low training period). Several prospective studies using moderate endurance training regimens for eight to 15 weeks have reported no significant elevation in NKCA relative to sedentary controls. ${ }^{82937}$ Together, these data imply that endurance exercise may have to be intensive and prolonged - that is, at athletic levels-before NKCA is chronically elevated. Researchers disagree on whether the higher NKCA is due to a greater concentration of circulating NK cells ${ }^{12}$ or an enhanced activity of each NK cell. ${ }^{11}{ }^{37}$ Blood NK cell concentrations were similar between our rowers and controls, indicating an increased NK cell lytic activity in the athletes.

MITOGEN INDUCED LYMPHOCYTE PROLIFERATIVE RESPONSES

Although mitogen induced lymphocyte proliferative responses have been reported to be increased in elderly male and female endurance athletes relative to age matched controls, ${ }^{37} 38$ this has not consistently been reported in young and middle aged adults. ${ }^{9-12}$ Baj et al reported no difference between elite cyclists and non-athletes during low training periods (March), but increased levels in the athletes for the mitogens PHA and anti-CD3 monoclonal antibody (but not the mitogens concanavalin A or pokeweed mitogen) during intensive training. Generation of interleukin-2 (a cytokine released by activated lymphocytes), however, was suppressed in the athletes compared with controls during intensive training. These data contrast with those of Tvede et al, ${ }^{12}$ who found no difference in mitogen induced lymphocyte proliferative responses between athletes and non-athletes during either low or high training periods. Nieman et $a l^{1011}$ were unable to establish any difference between runners (both collegiate and middle aged) and non-athletes with respect to mitogen induced lymphocyte proliferative responses. Part of the explanation for these disparate findings may be assay methodology (whole blood compared with separated cell assays). The whole blood method provides data that are purported to relate more closely to conditions in vivo, although this hypothesis has not yet been sufficiently researched. ${ }^{32}$

NEUTROPHIL FUNCTION AND CYTOKINES

No investigator has reported increased neutrophil function (either phagocytic ability or oxidative burst) among athletes compared with non-athletes. ${ }^{14-17}$ Instead, during periods of high intensity training, neutrophil function has been reported to be suppressed in athletes. This is especially apparent in the studies by Hack et $a l^{14}$ and Baj et $a l,{ }^{9}$ in which neutrophil function in athletes was similar to that in controls during periods of low training workloads, but significantly suppressed during the summer months of intensive training. Pyne et $a l^{15}$ reported that elite swimmers undertaking intensive training have a significantly lower neutrophil oxidative activity at rest than do age and sex matched sedentary subjects, and that function is further suppressed during periods of strenuous training before national level competition. No evidence of impaired granulocyte/monocyte phagocytosis and oxidative burst activity was found in our group of elite female rowers three months before the 1998 World Championships. Discrepancies between the few studies available may be due in part to differences in assay methodology, the type of athlete studied, and the time of year.

We are unaware of any studies that have compared plasma cytokine concentrations in 
athletes and non-athletes. Our data suggest no differences in plasma pro-inflammatory and anti-inflammatory cytokine levels between rowers and non-athletes.

\section{RELATION TO INFECTION HISTORY}

Despite differences in NKCA and whole blood PHA induced lymphocyte proliferative responses, URTI infection rates were similar between rowers and non-athletes, and none of the immune parameters measured correlated with the number of URTI symptom days. Other investigators have also had little success in linking variance in resting immunity (blood compartment) to incidence of infection. ${ }^{15}{ }^{18-21}$ Two small studies indicate that salivary $\operatorname{IgA}$ concentration may be related to infection risk in athletes, but the data at this time are unconvincing. ${ }^{39}{ }^{40}$ Although further research is warranted using larger subject numbers, the complex nature of the immune system makes it improbable that a single marker of immune function will emerge as a predictor of URTI risk in athletic populations.

\section{CONCLUSION}

Few cross sectional comparisons of immunity in athletes and non-athletes have been published; most include only a few immune measures, and none have focused on young adult females. In this comprehensive cross sectional comparison of 20 elite female rowers and 19 female non-athletes, we measured a group difference for NKCA and PHA induced proliferative response, but no other measures of immune function. These variances in blood measures of immunity, however, were unrelated to a two month history of URTI. We conclude that with the exception of NKCA and PHA induced proliferative response, the immune systems of female rowing athletes and non-athletes were more similar than disparate. In addition, during the time period (spring) of this study, no difference was measured in URTI symptomatology. This work was funded by The United States Olympic
Committee (One Olympic Plaza, Colorado Springs, CO 80909-5760, USA). We wish to acknowledge the assistance of the following in this research project: Cathy L Hisey, Judy C the following in this research project: Cathy L Hisey
Holbeck, Catherine T Gaffney, and Wayne J Kelin.

Holbeck, Catherine T Gaffney, and Wayne J Kelin.
Contributors: D N, the principal investigator of this research Contributors: $\mathrm{D} \mathrm{N}$, the principal investigator of this research
project, initiated and coordinated the formulation of the project, initiated and coordinated the formulation of the
primary study hypothesis, discussed core ideas, designed the protocol, and participated in data collection and analysis, and writing of the paper. S N-C, the co-investigator of this research project, initiated and coordinated the formulation of the primary study hypothesis, discussed core ideas, designed the protocol, and participated in data collection and analysis, and writing of the paper. O F participated in the study design, coordinated the staff conducting the immune assays, and edited the paper. $\mathrm{D} \mathrm{H}$ participated in the design and execution of the project, data collection and analysis, and edited the paper. MS coordinated the subject recruitment process, and participated in data collection and analysis, and edited the paper. J H participated in the study design, data collection and analysis, participated in the study design, data collection and analysis, and edited the paper. R S participated in the study design, data collection and analysis, and edited the paper. M B participated
in the study design, data collection and analysis, and edited the in the study design, data collection and analysis, and edited the
paper. M A participated in the study design, data collection and paper. M A participated in the study design, data collection and
analysis, and edited the paper. B S participated in the study analysis, and edited the paper. B S participated in the study
design, data collection and analysis, and edited the paper. R T design, data collection and analysis, and edited the paper. R T
participated in the study design, data collection and analysis, participated in the study design, data collection and
and edited the paper. Guarantors: D N and S N-C.

1 Nieman DC, Johanssen LM, Lee JW, et al. Infectious episodes in runners before and after the Los Angeles Marathon. J Sports Med Phys Fit 1990;30:316-28.

2 Peters-Futre EM. Vitamin C, neutrophil function, and upper respiratory tract infection risk in distance runners: the missing link. Exercise and Immunology Reviews 1997;3: $32-52$.
3 Nieman DC. Exercise immunology: practical applications. Int $\mathcal{Y}$ Sports Med 1997;18(suppl 1):S91-100.

4 Pedersen BK, Bruunsgaard H. How physical exercise influences the establishment of infections. Sports Med 1995;19: 393-400.

5 Foster C. Monitoring training in athletes with reference to overtraining syndrome. Med Sci Sports Exerc 1998;30: 1164-8.

6 Nieman DC. Effects of athletic training on infection rates and immunity. In: Kreider RB, Fry AC, O'Toole M, eds. Overtraining in sport. Champaign, IL: Human Kinetics, 19vertraining in $193-217$.

7 Shephard RJ, Kavanagh T, Mertens DJ, et al. Personal health benefits of Masters athletics competition. Br f Sports Med 1995;29:35-40.

8 Nieman DC, Pedersen BK. Exercise and immune function: recent developments. Sports Med 1999;27:73-80.

9 Baj Z, Kantorski J, Majewska E, et al. Immunological status of competitive cyclists before and after the training season. Int F Sports Med 1994;15:319-24.

10 Nieman DC, Brendle D, Henson DA, et al. Immune function in athletes versus nonathletes. Int 7 Sports Med 1995; 16:329-33.

11 Nieman DC, Buckley KS, Henson DA, et al. Immune function in marathon runners versus sedentary controls. Med Sci Sports Exerc 1995;27:986-92.

12 Tvede N, Steensberg J, Baslund B, et al. Cellular immunity in highly-trained elite racing cyclists and controls during periods of training with hig

13 Pedersen BK, Tvede N, Christensen LD, et al. Natural killer cell activity in peripheral blood of highly trained and untrained persons. Int $\mathcal{F}$ Sports Med 1989;10:129-31.

14 Hack V, Strobel G, Weiss M, et al. PMN cell counts and phagocytic activity of highly trained athletes depend on phagocytic activity of highly trained athletes
training period. $\mathcal{F}$ Appl Physiol $1994 ; 77: 1731-5$.

15 Pyne DB, Baker MS, Fricker PA, et al. Effects of an intensive 12-wk training program by elite swimmers on neutrophil oxidative activity. Med Sci Sports Exerc 1995;27:536-42.

16 Smith JA, Telford RD, Mason IB, et al. Exercise, training and neutrophil microbicidal activity. Int $\mathcal{F}$ Sports Med 1990; 11:179-87.

17 Lewicki R, Tchórzewski H, Denys A, et al. Effect of physical exercise and some parameters of immunity in conditioned sportsmen. Int F Sports Med 1987;8:309-14.

18 Pedersen BK, Rohde T, Zacho M. Immunity in athletes. $f$ Sports Med Phys Fitness 1996;36:236-45.

19 Mackinnon LT. Immunity in athletes. Int 7 Sports Med 1997;18(suppl 1):S62-8

20 Mackinnon, LT, Hooper SL, Jones S, et al. Hormonal, immunological, and hematological responses to intensified training in elite swimmers. Med Sci Sports Exerc 1997;29: $1637-45$.

21 Nieman DC. Immune response to heavy exertion. $\mathcal{F} \mathrm{Appl}$ Physiol 1997;82:1385-94.

22 Hagerman FC. Applied physiology of rowing. Sports Med 1984;1:303-26.

23 Nielsen HB, Secher NH, Christensen NJ, et al. Lymphocytes and NK cell activity during repeated bouts of maximal exercise. Am f Physiol 1996;271:R222-7.

24 Secher NH. Physiological and biomechanical aspects of rowing. Implications for training. Sports Med 1993;15:2442 .

25 Steinacker JM, Lormes W, Lehman M, et al. Training of rowers before world championships. Med Sci Sports Exerc 1998;30:1158-63.

26 Snegovskaya V, Viru A. Elevation in cortisol and growth hormone levels in the course of further improvement of performance capacity in trained rowers. Int $\mathcal{F}$ Sports Med 1993;14:202-6.

27 Castell LM, Poortmans JR, Newsholme EA. Does glutamine have a role in reducing infections in athletes? Eur f Appl Physiol 1996;73:488-51.

28 Budgett RG, Fuller GN. Illness and injury in international oarsmen. Clin $\mathcal{f}$ Sports Med 1989;1:57-61.

29 Nieman DC, Nehlsen-Cannarella SL, Henson DA, et al. Immune response to exercise training and/or energy restriction in obese females. Med Sci Sports Exerc 1998;30: 679-86.

30 Kramer JF, Leger A, Paterson DH, et al. Rowing performance and selected descriptive, field, and laboratory variables. Canadian fournal of Applied Physiology 1994;19: 174-84.

31 Storer TW, Davis JA, Caiozzo VJ. Accurate prediction of $\mathrm{VO}_{2 \max }$ in cycle ergometry. Med Sci Sports Exerc 1990;22: $704-12$.

32 Bloemena E, Roos MTL, Van Heijst JLAM, et al. Whole-blood lymphocyte cultures. F Immunol Methods 1989;122:161-7.

33 Bryant J, Day R, Whiteside TL, et al. Calculation of lytic units for the expression of cell-mediated cytotoxicity. $\mathcal{F}$ Immunol Methods 1992;146:91-103.

34 Whiteside TL, Bryant J, Day R, et al. Natural killer cytotoxicity in the diagnosis of immune dysfunction: criteria for a reproducible assay. F Clin Lab Anal 1990;4:102-14.

35 Fazio AF. A concurrent validation study of the NCHS General Well-being Schedule. Vital and health statistics series 2, Number 73, DHEW Publication No (HRA) 78-1347. Hyattsville, MD: National Center for Health Statistics, US Public Health, 1978 .

36 McDowell I, Newell C. Measuring health. New York: Oxford University Press, 1996:206-13. 
37 Nieman DC, Henson DA, Gusewitch G, et al. Physical activity and immune function in elderly women. Med Sci activity and immune functio

38 Shinkai S, Kohno H, Kimura K, et al. Physical activity and immune senescence in men. Med Sci Sports Exerc 1995;27: $1516-26$.
39 Mackinnon LT, Ginn EM, Seymour GJ. Temporal relationship between decreased salivary IgA and upper respiratory tract infection in elite athletes. Aust f Sci Med Sport 1993;25:94-9.

40 Pedersen BK, Nieman DC. Exercise immunology: integration and regulation. Immunol Today 1998;19:204-6.

\section{Take home message}

Do the immune systems of endurance athletes and non-athletes function differently? Although the epidemiological data on exercise and infection risk suggest that disparities should exist, attempts thus far to compare resting immune function in athletes and non-athletes have failed to provide compelling evidence that athletic endeavour is linked to clinically important changes in immunity. Even when significant changes in the concentration and functional activity of immune parameters have been observed in athletes, investigators have had little success in linking these to altered rates of infection and illness. Of all immune cells, natural killer cells appear to be the most affected by athletic endeavour, but in a positive way. In other words, the elevated natural killer cell function often reported in athletes should enhance host protection against certain types of virus and cancer cell. Nonetheless, in this study, we report that URTI rates were similar in female elite rowers and non-athletes during a two month period (winter/ spring) despite substantially higher natural killer function in the rowers (1.6-fold above that of controls).

\section{British Association of Sport and Exercise Medicine Annual Congress 2000}

3-5 November 2000; Tewkesbury, Worcestershire

\section{Call for abstracts}

The BASEM 2000 congress committee invite submissions of abstracts for the presentation of short papers and posters. All abstracts will be peer reviewed externally and anonymously and those selected may be published in the British Fournal of Sports Medicine. Awards will be presented, including the BASEM Young Researchers Award, presented to the best paper from an author less than 10 years qualified. Those not selected for oral presentation will be invited to present a poster, or poster only presentations may also be submitted. There will be a poster award presented.

The short paper and poster session for this annual conference has been well received by the delegates and is considered an important forum for discussion and debate in current research in sport and exercise medicine. Changes have been made to this year's conference format to allow more emphasis to be placed on these academic presentations.

To indicate a possible submission and to receive details on the exact abstract format required, please contact: Mrs Sue Roberts, BASEM Company Office, 12 Greenside Avenue, Frodsham, Cheshire WA6 7SA. Tel/fax: 01928 732961; email: basemoffice@compuserve.com; website: www.phmcs.com/basem

Please note: the final submission date for completed abstracts will be Friday 4 August 2000 . 